\title{
A Statistical Study of Wind Gusts in Japan Using Surface Observations
}

\author{
Wataru MASHIKO \\ Meteorological Research Institute, Japan Meteorological Agency, Tsukuba, Japan
}

(Manuscript received 20 March 2018, in final form 22 September 2018)

\begin{abstract}
In this study, the characteristics of wind gusts in Japan in the period from 2002 to 2017 were examined using surface meteorological data recorded at 151 weather observatories throughout Japan. This study does not focus on particular phenomena, such as tornadoes and downbursts, which cause wind gusts. A wind gust is defined on the basis of the gust factor and the amount of increase and decrease of the 3-s mean wind speed from the 10-min mean wind speed. A total of 3,531 events were detected as wind gusts. The frequency of wind gusts with more than $25 \mathrm{~m} \mathrm{~s}^{-1}$ averaged across all observatories is 0.97 per year, which is four or five orders of magnitude higher than the tornado encounter probability in Japan. The frequency of wind gusts in the coastal region is approximately three times higher than that in the inland area. Wind gusts occur most frequently in September and least frequently in June. Wind gusts have high activities during daytime, especially in the afternoon. Approximately half of the events are the typhoon-associated wind gusts (WGTYs), which occurred within a radius of $800 \mathrm{~km}$ from the typhoon center. Most of the WGTYs occur from August to October. Approximately half of the WGTYs occur in the right-front quadrant of a typhoon with respect to the typhoon motion. The frequency of WGTYs is high in western Japan, whereas the northern and eastern parts of Japan are characterized by a high frequency of wind gusts without a typhoon. In addition, persistent strong winds, which meet the same conditions as wind gusts but without a rapid decrease in the wind speed, were investigated. The frequency of such strong winds is high on the Japan Sea coast, especially in December. The effects of the observational environment on the frequency of wind gusts were also discussed.
\end{abstract}

Keywords wind gust; strong wind; surface observation

Citation Mashiko, W., 2019: A statistical study of wind gusts in Japan using surface observations. J. Meteor. Soc. Japan, 97, 39-54, doi:10.2151/jmsj.2019-001.

\section{Introduction}

There is still a lot of uncertainty regarding the statistical characteristics of wind gusts, such as frequency and spatiotemporal distribution. Although the Japan Meteorological Agency (JMA) has been creating a database about severe winds and tornadoes (hereafter JMA-DB, available at JMA's official homepage: http://www.data.jma.go.jp/obd/stats/data/bosai/tornado/

Corresponding author: Wataru Mashiko, Meteorological Research Institute, Japan Meteorological Agency, 1-1 Nagamine, Tsukuba, Ibaraki 305-0052, Japan

E-mail: wmashiko@mri-jma.go.jp

J-stage Advance Published Date: 5 October 2018 index.html), the data are largely affected by the recent increase in reports of sightings from the public and JMA's recent enhancement of damage surveys on severe wind events (Nakazato 2016). The statistical studies of tornadoes in Japan (e.g., Niino et al. 1997), the United States (e.g., Agee and Larson 2016; Krocak and Brooks 2018), and Europe (e.g., Antonescu et al. 2016, 2017) also have the same problem as the JMADB.

Meanwhile, there have been only a few reports on statistical analyses of wind gusts using surface observational data. This is due to the difficulty in observing wind gusts using surface data recorded at a sparse time interval at a limited number of weather stations, 
because wind gusts rarely occur and have quite a small spatiotemporal scale. However, several previous studies using surface observations in a certain region revealed that wind gusts occur more frequently than expected. Kobayashi et al. (2008) and Kobayashi et al. (2012) statistically investigated wind gusts using only one weather station on the Japan Sea coast during two winter seasons and detected 157 and 237 events, respectively. They showed that most of the wind gusts were accompanied by convective clouds and a temperature drop. Kusunoki et al. (2010) examined the frequency of wind gusts in the Shonai Plain on the Japan Sea side during a winter season and found it more than two orders of magnitude higher than that of tornadoes shown in Niino et al. (1997). Taniwaki et al. (2012) also detected more than 9,000 gust events in the Shonai Plain over three years using 12 ultrasonic anemometers, discovering that most of the wind gusts occurred in winter under prevailing northwesterly wind during a cold air outbreak. Tomokiyo and Maeda (2016) investigated gusty winds in Kyusyu Island, western Japan, using surface data at 123 weather stations and detected 1,298 wind gusts over five years.

The main objective of this study is to clarify the frequency and spatiotemporal distribution of wind gusts throughout Japan by statistically analyzing the surface observational data of the last 16 years. This is the first study in which detailed data from a lot of observatories distributed all over Japan are statistically analyzed for such a long period. This study does not focus on particular phenomena, such as tornadoes and downbursts, which cause wind gusts, unlike the previous studies (Wakimoto 1985; Kobayashi et al. 2008, 2012; Kusunoki 2010). The understanding of statistical characteristics of wind gusts is very important for science and mitigation of wind-related disasters. The wind gust events that were detected in this analysis could also complement the inhomogeneous JMA-DB. Moreover, this study is expected to lead to new findings and a better understanding of wind gust phenomena.

The remainder of this paper is organized as follows. The analytical method that is used in this study is presented in Section 2. Section 3 shows the statistical features of wind gusts and persistent strong winds accompanied by an abrupt increase in the wind speed. Section 4 discusses the effects of the observatory environment on the wind gusts. Finally, the results are summarized in Section 5.

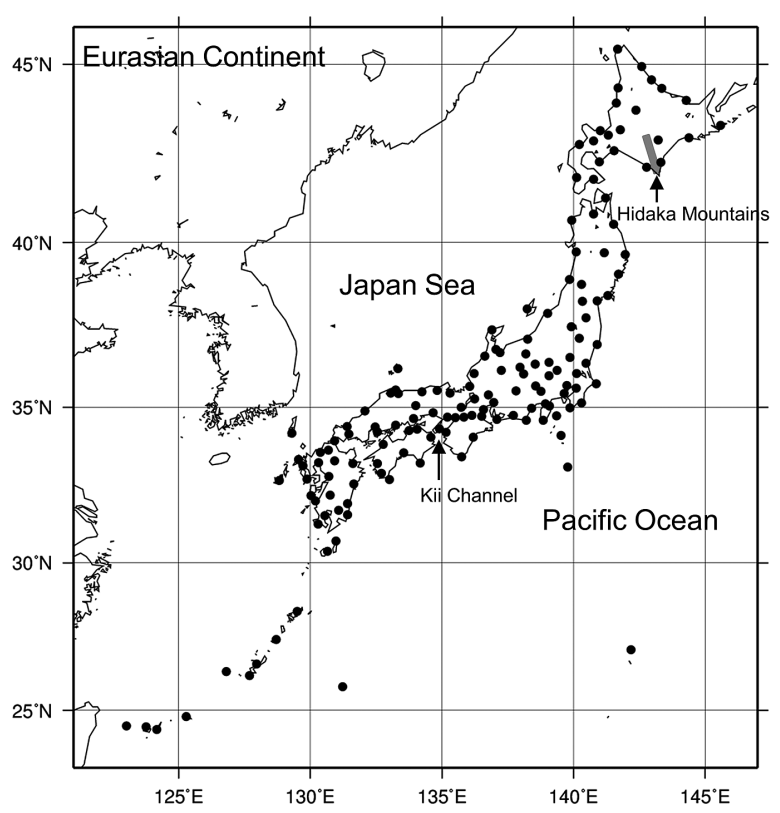

Fig. 1. Geographical locations of JMA's weather observatories. The specific geographical locations referred to in the text are also shown.

\section{Analytical method}

\subsection{Data}

In this study, wind gusts in Japan were statistically examined using one-minute interval surface meteorological data at 151 weather observatories ${ }^{1}$ of the JMA from 2002 to 2017. These weather observatories are deployed all over Japan, including isolated island areas, although they are densely distributed in the coastal regions (Fig. 1).

The one-minute dataset includes not only the 10 -min mean wind speed of the previous $10 \mathrm{~min}$, but also the maximum 3-s mean wind speed (after December 4,2007 ) or 0.25 -s mean wind speed (before December 4, 2007) in the previous $1 \mathrm{~min}$. In order to ensure coherence with the 3-s mean wind speed in this study, the 0.25 -s mean wind speed data before December 4, 2007 are multiplied by 0.9, according to the statistical survey of the JMA (2007).

\footnotetext{
${ }^{1}$ As of 2017 , the JMA has 155 weather observatories. Four observatories (Mount Aso, Oku-Nikko, Unzendake, and Minamitori Island) were excluded from this study because of a lot of missing data and/or anomalous values caused by the effect of the mountainous topography around the observatories.
} 


\subsection{Definition of wind gust}

There is no clear definition of wind gust, although the American Meteorological Society (AMS) Glossary of Meteorology (Glickman 2000) defines a gust as "a sudden, brief increase in the speed of the wind". This study objectively defines a wind gust based on the observed wind speed data, regardless of the phenomena causing a wind gust.

Most previous studies about wind gusts focused on not only the maximum instantaneous wind speed, but also the amount of increase and decrease in the wind speed and/or gust factor (Wakimoto 1985; Kobayashi et al. 2008, 2012; Kusunoki et al. 2010; Tomokiyo and Maeda 2016). The gust factor is usually defined by the ratio of the maximum instantaneous wind speed to the 10-min mean wind speed shortly before the wind gust.

This study imposes the following conditions on the wind gust definition:

$$
\begin{aligned}
& W_{3 \mathrm{~s}}(t)> \operatorname{Pre}-W_{10 \mathrm{~m}}(t)+15, \\
& W_{3 \mathrm{~s}}(t) / \operatorname{Pre}-W_{10 \mathrm{~m}}(t)>2.0, \\
& W_{3 \mathrm{~s}}(t)>\left(W_{3 \mathrm{~s}}(t-3)+W_{3 \mathrm{~s}}(t-2)\right. \\
&\left.+W_{3 \mathrm{~s}}(t-1)\right) / 3+10, \\
& W_{3 \mathrm{~s}}(t)> \text { Post } W_{10 \mathrm{~m}}(t)+10,
\end{aligned}
$$

where $W_{3 \mathrm{~s}}(t)$ denotes the maximum 3-s mean wind speed in the previous $1 \mathrm{~min}$ at time $t$, and Pre- $W_{10 \mathrm{~m}}(t)$ and Post- $W_{10 \mathrm{~m}}(t)$ are the 10-min mean wind speeds just before and after the wind gust at time $t$, respec- tively. These conditions, where the gust factor and the amounts of increase and decrease in the wind speed before and after the wind gust are much higher than the criteria of previous studies (Wakimoto 1985; Kobayashi et al. 2008, 2012; Kusunoki et al. 2010; Tomokiyo and Maeda 2016), are schematically shown in Fig. 2. Condition (2) specifies that the gust factor must be larger than two. The threshold of the gust factor satisfying condition (1) is illustrated in Fig. 2b. The gust factor significantly increases as the 10-min mean wind speed decreases below $15 \mathrm{~m} \mathrm{~s}^{-1}$, which indicates that condition (1) imposes a very high gust factor. Condition (3) excludes strong turbulent winds that rarely occur. If multiple wind gusts are detected within 3 min under these conditions, they are regarded as one wind gust event. The time sequence diagram of the wind speed that satisfies all conditions (1)-(4) exhibits a spike shape as shown in Fig. 3a. In contrast, the wind speed trace, which satisfies conditions (1), (2), and (3), but not (4), shows a step shape due to the strong and persistent wind occurring after a rapid increase in the wind speed (Fig. 3b). This type of strong wind was also extracted as "step-type strong wind" (STPSW) in this study, because it should be considered from the point of view of disaster prevention.
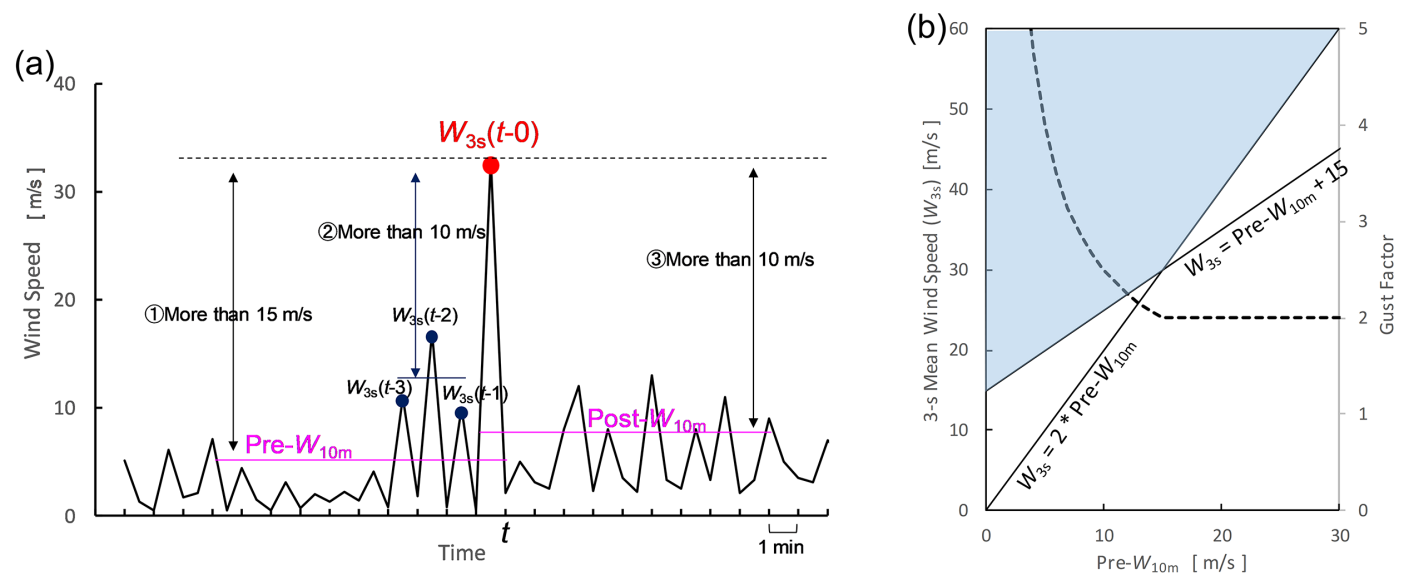

Fig. 2. (a) A hypothetical wind speed trace for the wind gust defined in this study. $W_{3 \mathrm{~s}}(t-X)$ indicates a maximum 3 -s mean wind speed in the previous $1 \mathrm{~min}$, occurring $X$ min prior to the wind gust at time $t$. Pre- $W_{10 \mathrm{~m}}$ is the 10 min mean wind speed prior to the wind gust of $W_{3 \mathrm{~s}}(t-0)$, and Post- $W_{10 \mathrm{~m}}$ is the 10 -min mean wind speed after the wind gust of $W_{3 \mathrm{~s}}(t-0)$. Pre- $W_{10 \mathrm{~m}}$ and Post- $W_{10 \mathrm{~m}}$ are shown as pink bars; their horizontal positions indicate the periods of the 10-min mean winds. (b) The relationship between the 3-s mean wind speed and Pre- $W_{10 \mathrm{~m}}$, which meets the conditions for wind gust in this study (blue shaded area). The threshold of gust factor for wind gust is plotted against Pre- $W_{10 \mathrm{~m}}$ by the broken line. 

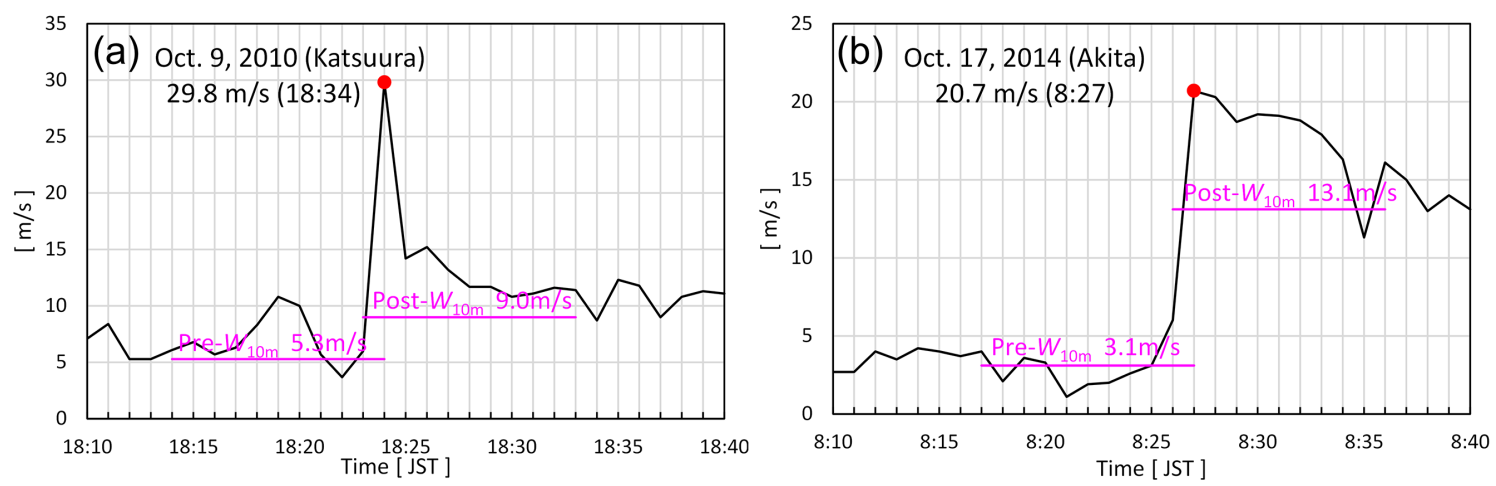

Fig. 3. Examples of the wind speed trace for (a) wind gust and (b) STPSW represented by small red circles. The black line indicates the time series of the maximum 3-s mean wind speed in the previous 1 min. The values of Pre- $W_{10 \mathrm{~m}}$ and Post- $W_{10 \mathrm{~m}}$ are shown by pink bars; their horizontal positions indicate the periods of the 10-min mean winds.

Table 1. Number of wind gusts classified into seven categories according to the wind speed. Categories R0 to R5 correspond to the JEF scale of $0-5$. The wind speed of Rm is smaller than that of JEF0. The bottom row shows the WGTYs, which are defined as an event occurring within a radius of $800 \mathrm{~km}$ from the typhoon center.

\begin{tabular}{lccccccc}
\hline \multicolumn{1}{c}{ Rating } & $\mathrm{Rm}$ & $\mathrm{R} 0$ & $\mathrm{R} 1$ & $\mathrm{R} 2$ & $\mathrm{R} 3$ & $\mathrm{R} 4$ & $\mathrm{R} 5$ \\
\hline $\begin{array}{l}3 \mathrm{~s} \text { Wind Speed } \\
\left(W_{3 \mathrm{~s}}\right)\left[\mathrm{m} \mathrm{s}^{-1}\right]\end{array}$ & $W_{3 \mathrm{~s}}<25$ & $25 \leq W_{3 \mathrm{~s}}<39$ & $39 \leq W_{3 \mathrm{~s}}<53$ & $53 \leq W_{3 \mathrm{~s}}<67$ & $67 \leq W_{3 \mathrm{~s}}<81$ & $81 \leq W_{3 \mathrm{~s}}<95$ & $95 \leq W_{3 \mathrm{~s}}$ \\
\hline $\begin{array}{l}\text { Number of Wind } \\
\text { Gusts }\end{array}$ & 1210 & 2197 & 120 & 4 & 0 & 0 & 0 \\
\begin{tabular}{l} 
Number of WGTYs \\
\hline
\end{tabular} & 401 & 1323 & 117 & 4 & 0 & 0 & 0 \\
\hline
\end{tabular}

\section{Results}

\subsection{Wind gusts \\ a. General feature}

A total of 3,531 wind gusts were detected at the weather observatories from 2002 to 2017 . The number of wind gusts is about twice as many as that listed in JMA-DB, which includes waterspouts. Seven wind gusts correspond to the actual events listed in JMADB, while about $9.1 \%$ of wind gusts (278 cases) occurred within a radius of $300 \mathrm{~km}$ and plus or minus

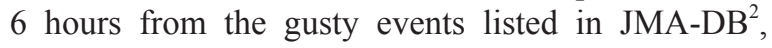
which is considered to be that the wind gusts occurred in the same synoptic environment as those listed in JMA-DB. This result suggests that JMA-DB includes only a small portion of wind gusts, whereas the wind gusts extracted in this study do not generally cover the

\footnotetext{
${ }^{2}$ The comparison between wind gusts extracted in this study and events listed in JMA-DB was conducted from January 1, 2002 to March 31, 2016, because the official data of JMA-DB since April 1, 2016 was not released at the time of this writing.
}

typical gusty events listed in JMA-DB; however, their synoptic environments have similarity to some extent.

As shown in Table 1, the wind gusts were classified into seven categories (Rm, R0, R1, R2, R3, R4, and R5) according to the wind speed. Categories R0-R5 correspond to the estimated wind speed of the Japanese Enhanced Fujita (JEF) scale of 0-5 (Tanaka 2016), respectively. The JEF scale was created on the basis of wind damage of vegetation and human created structures. However, it should be noted that the wind speed estimated by the JEF scale does not correspond to the actual wind speed because it is assessed on the assumption of horizontally oriented straight wind (Tamura 2016). The number of wind gusts significantly decreases from R0 to R2, while strong wind gusts ranked R3 or higher have not been observed. The weak wind gusts of Rm and R0 account for $96.5 \%$ of total wind gusts. Table 1 also shows wind gusts associated with a typhoon (WGTYs), which are defined as occurring within a radius of $800 \mathrm{~km}$ from the typhoon center. In this study, a typhoon includes an extratropical cyclone listed in the best track data 


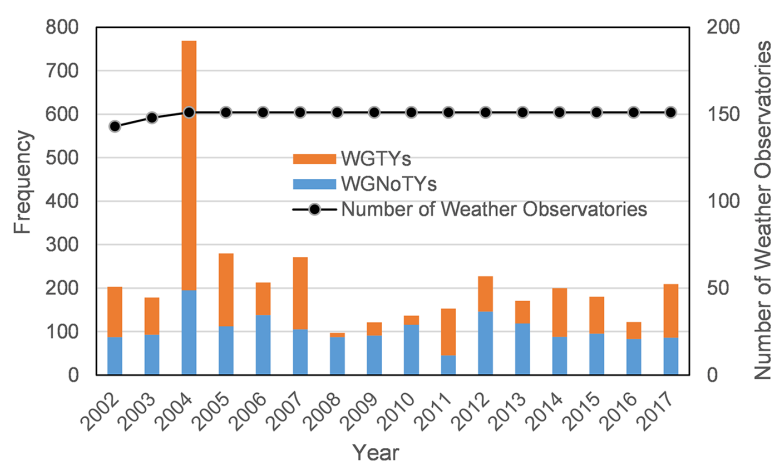

Fig. 4. Annual frequencies of wind gusts recorded at weather observatories from 2002 to 2017. The orange bars denote the frequencies of WGTYs and the blue bars show those of WGNoTYs. The line graph indicates the annual change in the number of weather observatories used in this study. For eight observatories in 2002 and three observatories in 2003, no data are available.

by the JMA, which undergoes extratropical transition from a typhoon. Approximately half of the wind gusts are WGTYs. Moreover, most of the strong wind gusts ranked R1 and R2 are WGTYs. This may indicate that these gusty winds cause a large portion of the wind damage due to tropical cyclones, as suggested by Wurman and Kosiba (2018).

The annual frequency of wind gusts is shown in Fig. 4. Roughly, 100-250 wind gusts were recorded each year, except for an outstanding number of 769 in 2004. It is estimated that the record-breaking 10 typhoon landfalls in Japan in 2004 caused a lot of wind gusts. The number of WGTYs largely fluctuates from year to year compared with wind gusts not asso-

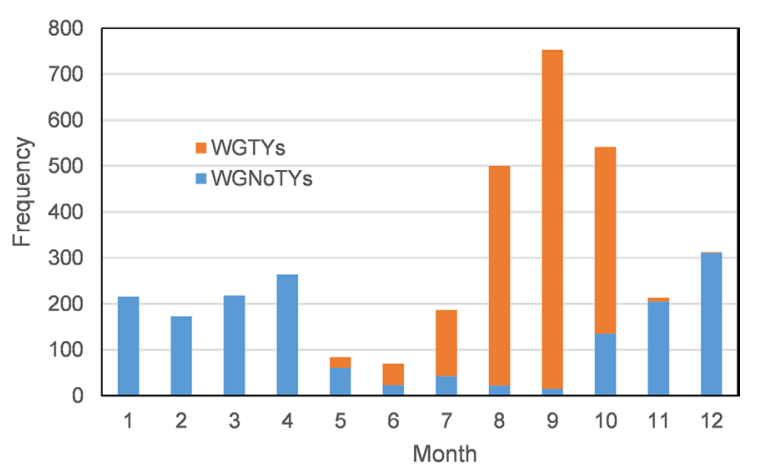

Fig. 5. Monthly frequencies of wind gusts recorded at weather observatories from 2002 to 2017. The orange bars denote the frequencies of WGTYs and the blue bars show those of WGNoTYs.

ciated with a typhoon (WGNoTYs). In contrast to the tornado frequency listed in the JMA-DB, there is no evidence of an increase of the frequency of wind gusts in the last ten years.

Figure 5 shows the monthly frequencies of wind gusts recorded at weather observatories from 2002 to 2017. Approximately $50.8 \%$ of the wind gusts occur from August to October, most of which are WGTYs. Wind gusts occur most frequently in September, which agrees with the tornado occurrence of the JMA-DB, and least frequently in June. There are two additional weak peaks in December and April, which are caused by WGNoTYs.

Figure 6 presents the diurnal variations of WGNoTYs and WGTYs. Both show diurnal variations with a high frequency approximately between 13:00 and 17:00 Japan Standard Time (JST; JST = $\mathrm{UTC}+9 \mathrm{~h}$ ), although the WGTYs show a random
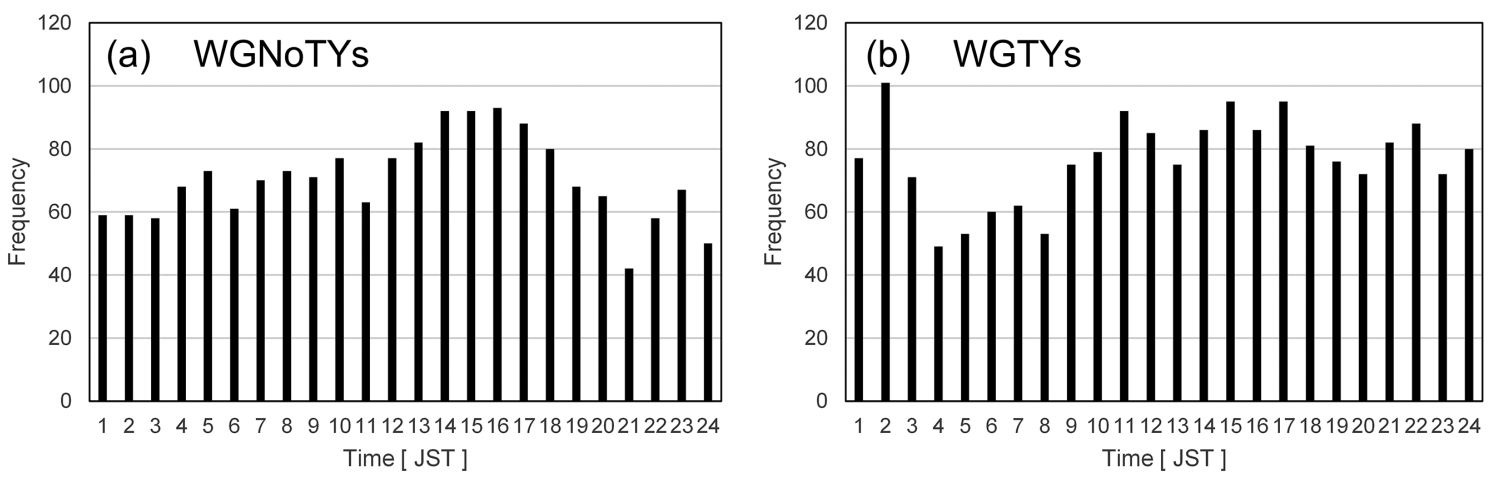

Fig. 6. Hourly frequencies of (a) WGNoTYs and (b) WGTYs at weather observatories from 2002 to 2017. Each bar indicates the number of wind gusts within the previous hour. 
fluctuation, which is probably caused by the timing of when typhoons affect Japan because of an insufficient sample number. A low frequency is found between 20:00 and 24:00 JST for WGNoTYs and between 03:00 and 08:00 JST for WGTYs. The diurnal variations are roughly similar to those of the tornado occurrences in Japan, as well as the mid-Atlantic region in the United States (Giordano and Fritsch 1991) and Europe (Rauhala et al. 2012; Kahraman and Markowski 2014; Groenemeijer and Kühne 2014; Antonescu et al. 2016). The high frequency of wind gust occurrences during the daytime (especially in the afternoon) probably reflects the unstable atmospheric conditions and higher activity of cumulus convection due to surface heating by solar radiation. However, the diurnal variations of wind gust occurrences in this study are quite small compared with those of the JMA-DB. The smaller frequency of tornado occurrence during nighttime in the JAM-DB might be partly caused by the smaller number of tornado eyewitnesses. It is interesting to note that the WGTYs also show diurnal variations, as shown in the outer region of a tropical cyclone (Schultz and Cecil 2009), in contrast to typhoon-associated tornadoes reported by Niino et al. (1997).

More than one WGTY tends to occur on the same day, compared to WGNoTY (not shown). This implies that typhoons are more likely to create a wide and persistent environment favorable for wind gust occurrences and cause multiple wind gusts in a single day. This feature is consistent with that of typhoon- and hurricane-associated tornadoes (Niino et al. 1997; Edwards 2012).

\section{b. Spatial distribution}

The geographical distribution of the annual frequency of wind gusts averaged from 2012 to 2017 is shown in Fig. 7a. It is evident that wind gusts occur all over Japan and that most wind gusts occur in coastal areas, including isolated small islands. Figure 8 shows the average annual frequency of wind gusts as a function of distance from the coastline. The Global Land Cover Characterization (GLCC) dataset of the U.S. Geological Survey was used to specify the coastline of Japanese archipelagos. The frequency of wind gust occurrences monotonically decreases from the coast to the inland. The frequency in the coastal regions is approximately three times higher than that in the inland areas.

The frequency averaged over all observatories is 1.47 per year. For categories equal to or higher than $\mathrm{R} 0$, the frequency is 0.97 per year, which is four or five orders of magnitude higher than the tornado encounter probability in Japan (Niino et al. 1997). Observatories with a high frequency of wind gusts are locally distributed, especially in the coastal region of the Pacific Ocean side. Among them, the frequency at the Ofunato and Hiroo observatories (see Fig. 7a for their locations) is rather high, although the JMA-DB shows that hazardous wind gusts almost never occurred around the observatories. In the coastal region of the Japan Sea side, the frequency of wind gusts is generally high. It should be noted that the observatories with high-frequency wind gusts do not necessarily correspond to those with climatologically strong winds (cf. Figs. 7a, b).

Figure $7 \mathrm{c}$ shows the annual number of occurrence days of wind gusts, which differs from the frequency shown in Fig. 7a because multiple wind gusts occur on the same day. On average, the number is 0.87 days per year. For categories equal to or higher than R0, the number is 0.54 days per year. Compared with the geographical distribution of the frequency shown in Fig. 7a, the number of days with wind gusts mainly decreases in western Japan (roughly west of longitude $137^{\circ} \mathrm{E}$ ), especially on the Pacific Ocean side. This indicates that those regions experience many days with multiple wind gusts.

The frequency of wind gusts is classified into WGNoTY and WGTY (Fig. 9). Southwestern Japan (roughly south of latitude $36^{\circ} \mathrm{N}$ ) experiences a high frequency of WGTYs, and northern Japan (roughly north of latitude $36^{\circ} \mathrm{N}$ ) has a low frequency of WGTYs. In contrast, WGNoTYs frequently occur in eastern and northern Japan (roughly east of longitude $137^{\circ} \mathrm{E}$ ) and on isolated small islands in the Japan Sea. These results indicate that western Japan experiences a high frequency of wind gusts caused by multiple WGTYs on the same days.

Figure 10 shows the geographical distribution of the seasonal variations of WGNoTYs. The coastal regions of the Japan Sea generally have high-frequency WGNoTYs in winter (Fig. 10a), as indicated by Taniwaki et al. (2012). This is likely because strong convective systems develop on the Japan Sea side in winter when cold air masses from the Eurasian Continent are transformed over the Japan Sea by large sensible and latent heat (e.g., Nagata et al. 1986; Mashiko et al. 2012). On the Pacific side, WGNoTYs most often occur in winter and spring, although the local variation is large (Figs. 10a, b). In summer, few WGNoTYs occur all over Japan (Fig. 10c). In autumn, northern Japan (roughly north of latitude $38^{\circ} \mathrm{N}$ ) experiences a high frequency of WGNoTYs (Fig. 10d), 

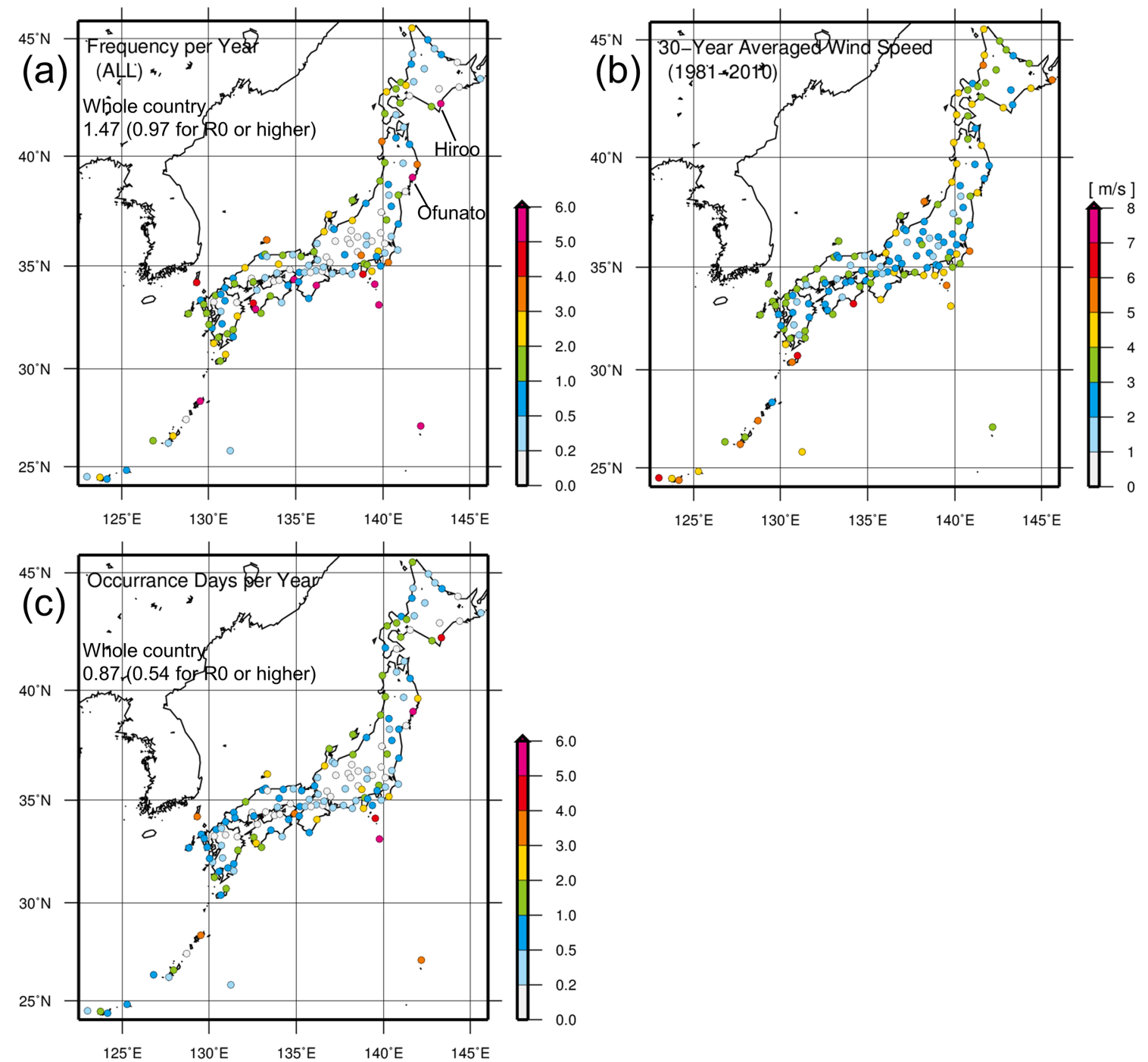

Fig. 7. (a) Annual frequency of wind gusts averaged from 2002 to 2017 at the weather observatories. (b) Averaged wind speed from 1981 to 2010 at the weather observatories. (c) As in (a) but for the annual number of occurrence days.

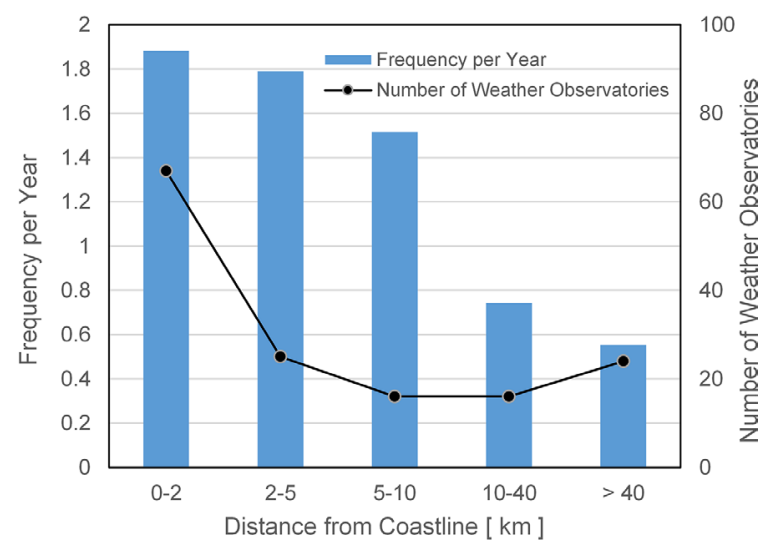

Fig. 8. Average annual frequency of wind gusts classified according to the distance from the coastline. The line graph indicates the number of weather observatories within the distance categories. Note that observatories whose distance categories changed because of anemometer relocation were omitted in this plot. 

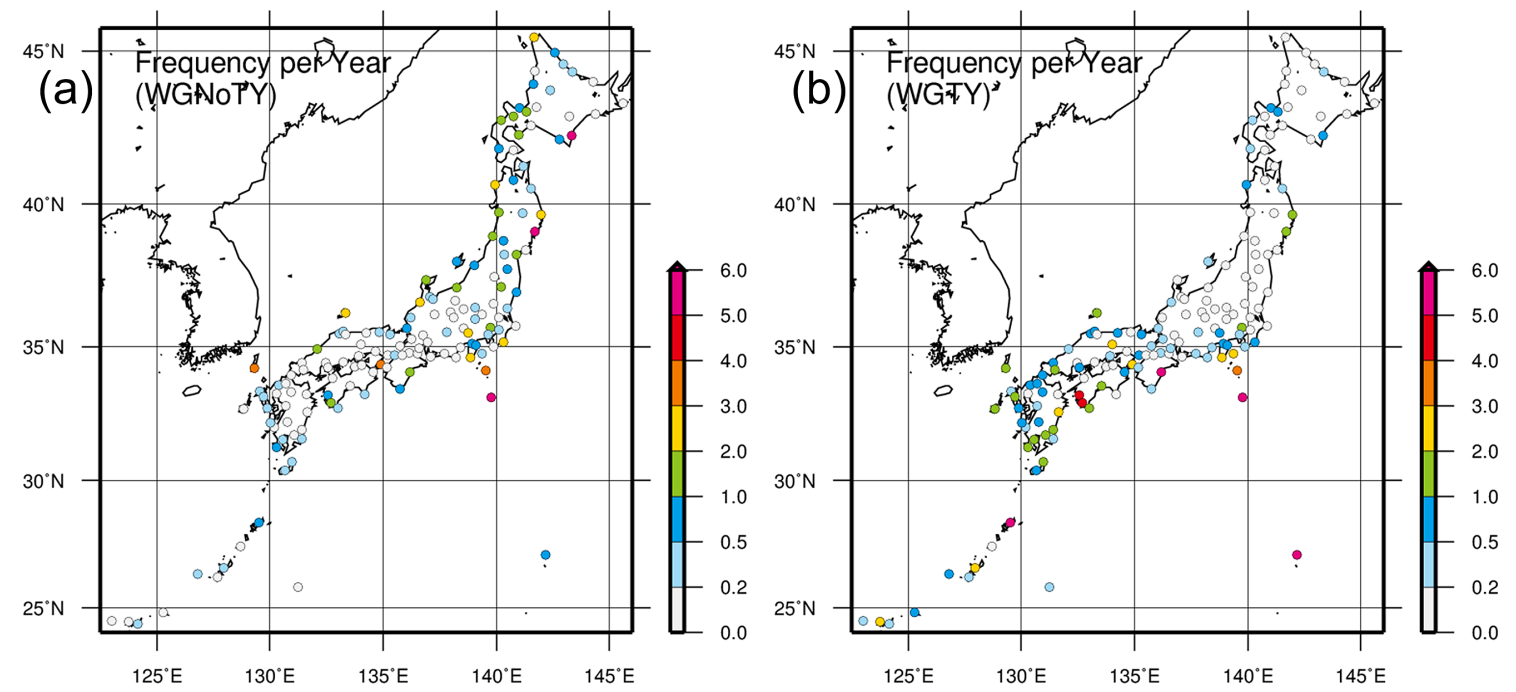

Fig. 9. Annual frequency of (a) WGNoTYs and (b) WGTYs at the weather observatories averaged from 2002 to 2017.

which is probably because those areas begin to be affected by enhanced convections due to cold air-mass outbreaks from the Eurasian Continent.

\section{c. WGTY distribution relative to the typhoon center}

As noted in Section 3.1a, WGTYs make up about half of the total wind gusts. Figure 11 shows the spatial distribution of WGTYs relative to the typhoon center. Approximately $48.2 \%$ of WGTYs occur in the right-front quadrant with respect to the typhoon motion, which is similar to hurricane-associated tornadoes (McCaul 1991; Schultz and Cecil 2009). The wind speed of WGTYs tends to increase near the centers of typhoons because of the superposition of gusty wind and the strong and persistent background flow associated with typhoon circulation.

The frequency of wind gusts have a peak from 100 to $250 \mathrm{~km}$ (Fig. 12), especially from 100 to $150 \mathrm{~km}$, which is located on the inner side compared with hurricane-associated tornadoes (McCaul 1991; Schultz and Cecil 2009). In the typhoon core region, wind gusts are likely strong and have quite a high frequency per unit area (Fig. 12). Thus, it is crucial to understand the associated phenomena for mitigation of windrelated disasters. Although there is still a lot of uncertainty with respect to meso- or microscale disturbances around the typhoon core, several possible phenomena causing those wind gusts can be considered, such as eyewall mesovortices (Mashiko 2005; Aberson et al. 2006), tornado-scale vortices in the eyewall (Wurman and Kosiba 2018), boundary layer rolls (Wurman and Winslow 1998), and tornadoes (McCaul 1991; Schultz and Cecil 2009). Specific phenomena that cause strong gusty winds within the typhoon core region should be identified in the future.

\section{d. Changes in the wind direction and temperature before and after wind gusts}

Figure 13 shows the frequencies of wind gusts according to wind direction changes before and after wind gusts. Note that the change in the wind direction using the 10-min mean wind does not reflect the wind gust itself but rather the environment or parent storm of the wind gust. Both WGNoTYs and WGTYs likely occur in an environment with a small wind direction change. Approximately $84.4 \%$ (75.0\%) of WGTYs (WGNoTYs) are accompanied by wind direction changes within 10 degrees. However, wind gusts with a clockwise change are more dominant. Approximately $35.8 \%(32.2 \%)$ of WGNoTYs (WGTYs) show a clockwise change, while $24.5 \%$ (19.7\%) exhibit a counterclockwise change. This trend suggests that wind gusts tend to occur when cyclonic disturbances pass through the northern side.

The frequency distribution of the temperature change before and after wind gusts is shown in Fig. 14. Most wind gusts, especially WGTYs, occur in an environment with a weak temperature gradient, similar to that of supercell tornadoes (e.g., Markowski et al. 2002). Approximately $91.6 \%$ (73.7\%) of WGTYs 

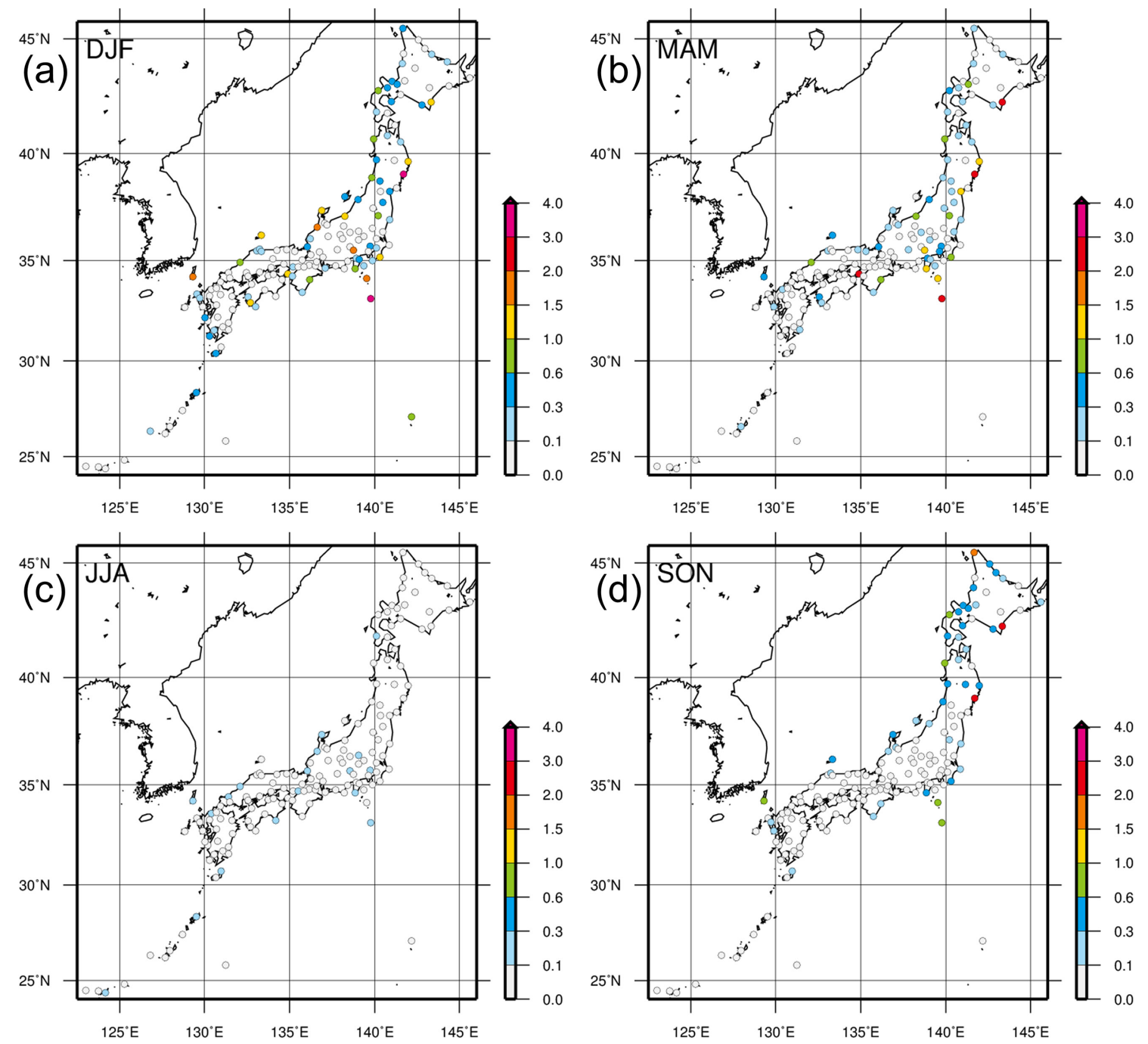

Fig. 10. Seasonal variation of WGNoTYs at the weather observatories, where WGNoTYs are classified into four periods: (a) December, January, and February; (b) March, April, and May; (c) June, July, and August; and (d) September, October, and November. Note that the unit is frequency per year.

(WGNoTYs) occur in an environment within a $0.5^{\circ} \mathrm{C}$ temperature change. This is probably due to the weak evaporative cooling from raindrops in the typhoon environment with a high humidity for the WGTYs, as in the environment of typhoon-associated minisupercell tornadoes (Mashiko et al. 2009). However, concerning WGNoTYs, wind gusts accompanied by a temperature drop account for a larger portion (54.1\%) of WGNoTYs than those associated with a temperature increase $(30.4 \%)$.

\subsection{STPSW}

Table 2 summarizes the frequency distributions of STPSWs categorized according to the wind speed. The total number of STPSWs is 190, which is fairly low compared with that of wind gusts. The frequency of STPSWs per year averaged over all observatories is 0.079 . Weak STPSWs ranked Rm occupy $78.9 \%$ of the total of STPSWs. Typhoon-associated STPSWs account for only $12.6 \%$, which contrasts with the much more frequent occurrence of WGTYs from August to October (cf. Figs. 5, 15). Approximately $64.7 \%$ of the STPSWs occur from November to 


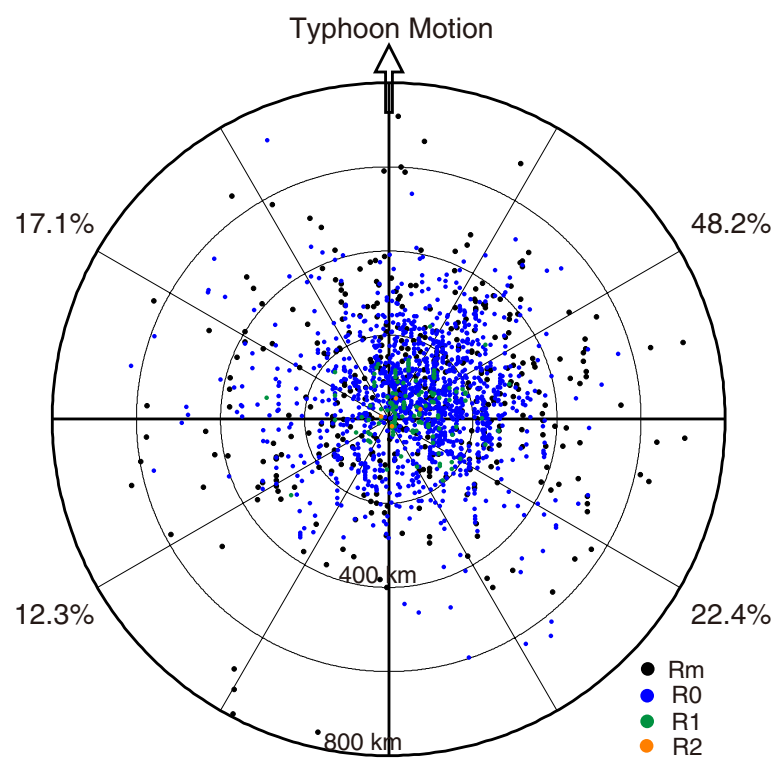

Fig. 11. Spatial distribution of WGTYs relative to the typhoon center. Note that the top of the sheet is the direction of typhoon motion. The colors indicate the intensity of wind gusts categorized in Table 1. The ratio of the number of WGTYs in each quadrant is also shown.

April, and there are no typhoon-associated STPSWs in this period. Also, STPSWs show two peaks in December and April, as well as a low frequency from June to August (Fig. 15). The trend of STPSWs is similar to that of the WGNoTYs; however, the peak of STPSWs in December is notable.

Figure 16 shows the annual frequency of STPSWs averaged from 2002 to 2017 at the weather observatories. The frequency is high in coastal regions, especially on the Japan Sea side in northern Japan (roughly north of latitude $36^{\circ} \mathrm{N}$ ). Observatories with highfrequency STPSWs do not necessarily correspond to those with high-frequency wind gusts (cf. Figs. 7a, 16), but have relatively usual strong winds (cf. Figs. $7 \mathrm{~b}, 16)$. Compared with wind gusts, there are fewer instances of multiple STPSWs occurring on the same day.

Figure 17 shows the average annual frequency of STPSWs classified according to the distance from the coastline. Similar to wind gusts, the frequency of STPSWs in coastal regions is approximately three times higher than in inland areas, although the frequency distribution shows some fluctuations due to the small sample number of STPSWs.

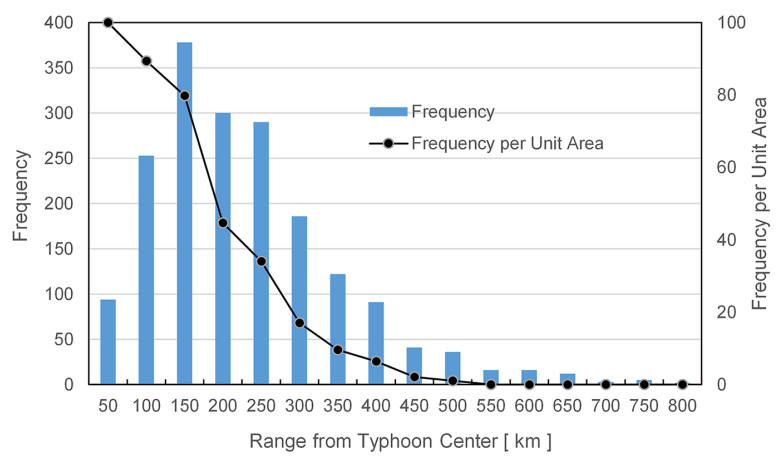

Fig. 12. Frequency of wind gusts as a function of a $50 \mathrm{~km}$ range from the typhoon center. The line graph indicates the frequency per unit area normalized on the basis of the innermost circle.

Figure 18 shows that the annual frequency distribution of STPSWs that are not associated with a typhoon can be classified into two periods: November-April and May-October. A large portion of STPSWs occur on the coast of the Japan Sea in the former period, when cold air mass outbreaks from the Eurasian Continent often occur and synoptic cold fronts or lowpressure troughs frequently pass over the Japanese archipelagos. This is reflected in changes of the wind direction and temperature before and after STPSWs. The changes in the wind direction are large compared with the wind gusts (cf. Figs. 13, 19a); 68.4\% of STPSWs exhibit a clockwise shift $(35.8 \%$ for WGNoTYs and $32.2 \%$ for WGTYs). The temperature changes are also significant (cf. Figs. 14, 19b); $63.7 \%$ of STPSWs show a temperature drop $(54.1 \%$ for WGNoTYs and $37.6 \%$ for WGTYs). The STPSWs with a temperature drop of more than $1{ }^{\circ} \mathrm{C}$ account for $40.5 \%$ of the total $(15.1 \%$ for WGNoTYs and $2.1 \%$ for WGTYs). It is also interesting that approximately $11.6 \%$ of the STPSWs are associated with a temperature rise of more than $1{ }^{\circ} \mathrm{C}(1.2 \%$ for WGNoTYs and $0.5 \%$ for WGTYs).

\section{Discussion}

In this study, data obtained by 151 JMA weather observatories were used for statistical analyses. However, the observational environments at the weather observatories, such as the anemometer height and surface roughness around the observatory, are quite different from each other. Based on previous studies (e.g., Kuwagata 1993), it has been suggested that the gust factor is sensitive to the value of $1 / \ln \left(z_{a} / z_{0}\right)$ at weather observatories under neutral atmospheric 

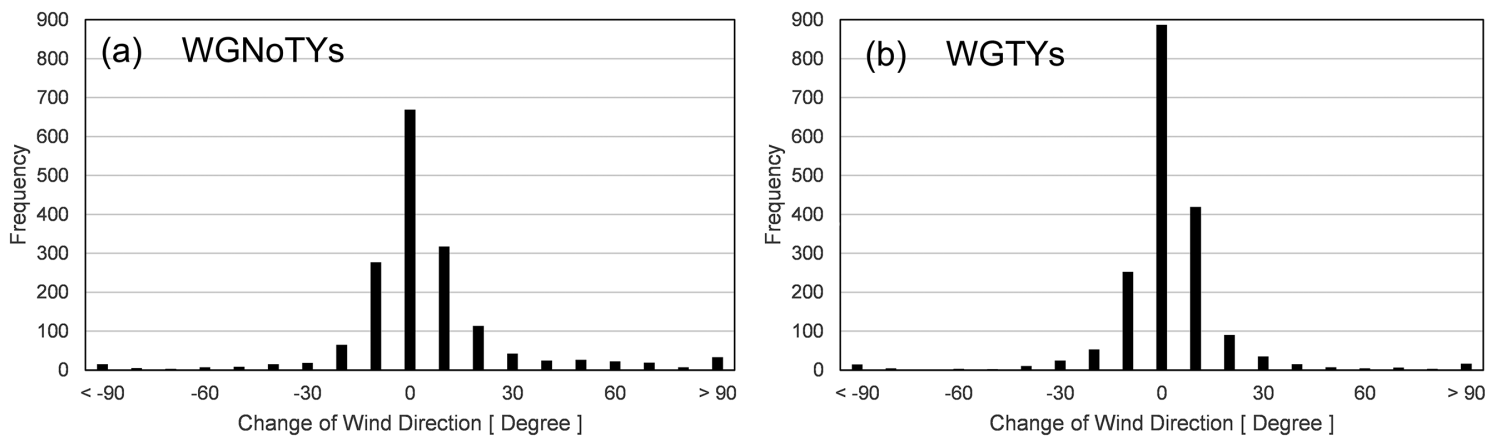

Fig. 13. Frequencies of (a) WGNoTYs and (b) WGTYs categorized by the 10-min mean wind direction change before and after wind gusts. The positive wind direction change indicates a clockwise shift with time. The period of averaging the wind direction before the wind gust is the same as that of Pre- $W_{10 \mathrm{~m}}$, and the period of averaging the wind direction after the wind gust is the same as that of Post- $W_{10 \mathrm{~m}}$. However, if the 5-min mean wind direction deviates by more than 90 degrees from the 10-min mean wind direction, the 5-min mean wind direction is used instead of the 10-min mean wind direction, which is JMA's operation of calculating the 10-min mean wind direction.
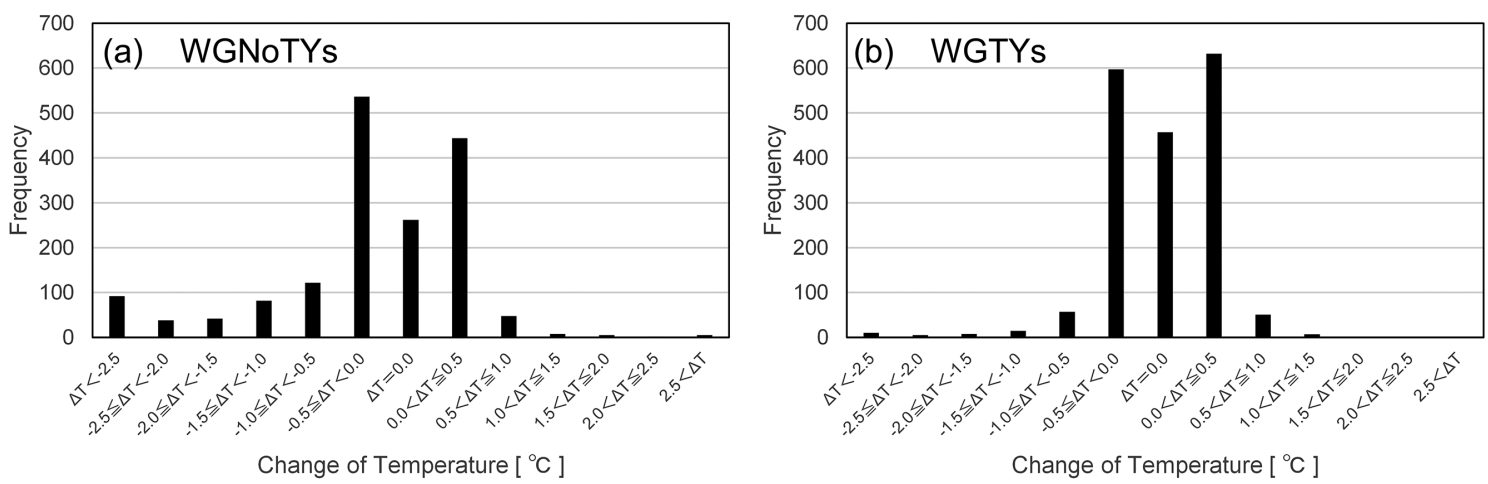

Fig. 14. Frequencies of (a) WGNoTYs and (b) WGTYs categorized by the 10-min mean temperature change before and after wind gusts. The positive temperature change indicates an increase with time. The period of averaging the temperature before the wind gust is the same as that of Pre- $W_{10 \mathrm{~m}}$, and the period of averaging the temperature after the wind gust is the same as that of Post- $W_{10 \mathrm{~m}}$. However, the 10-min mean temperature before and after the wind gusts is calculated using snapshot data at $1 \mathrm{~min}$ intervals.

Table 2. As in Table 1, but for STPSWs.

\begin{tabular}{|c|c|c|c|c|c|c|c|c|}
\hline Rating & $\mathrm{Rm}$ & R0 & R1 & $\mathrm{R} 2$ & R3 & R4 & R5 & \\
\hline $\begin{array}{l}3 \mathrm{~s} \text { Wind Speed } \\
\left(W_{3 \mathrm{~s}}\right)\left[\mathrm{m} \mathrm{s}^{-1}\right]\end{array}$ & $W_{3 \mathrm{~s}}<25$ & $25 \leq W_{3 \mathrm{~s}}<39$ & $39 \leq W_{3 \mathrm{~s}}<53$ & $53 \leq W_{3 \mathrm{~s}}<67$ & $67 \leq W_{3 \mathrm{~s}}<81$ & $81 \leq W_{3 \mathrm{~s}}<95$ & $95 \leq W_{3 \mathrm{~s}}$ & Total \\
\hline Number of STPSWs & 150 & 39 & 1 & 0 & 0 & 0 & 0 & 190 \\
\hline $\begin{array}{l}\text { Number of STPSWs } \\
\text { Associated with a } \\
\text { Typhoon }\end{array}$ & 13 & 10 & 1 & 0 & 0 & 0 & 0 & 24 \\
\hline
\end{tabular}




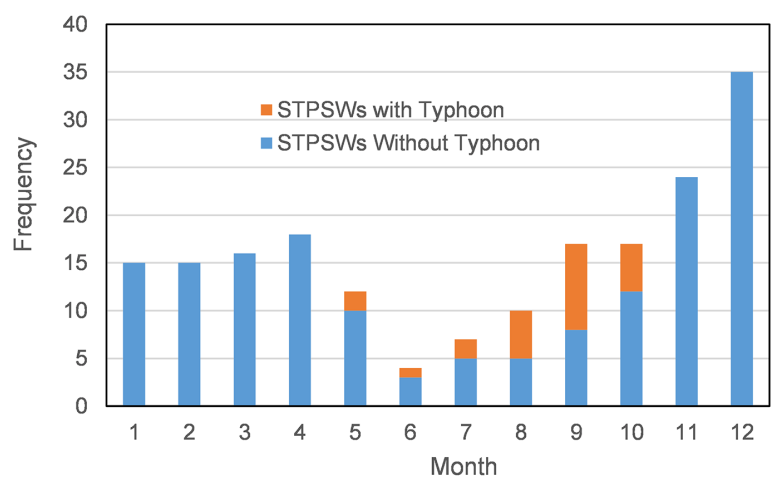

Fig. 15. As in Fig. 5, but for STPSWs.

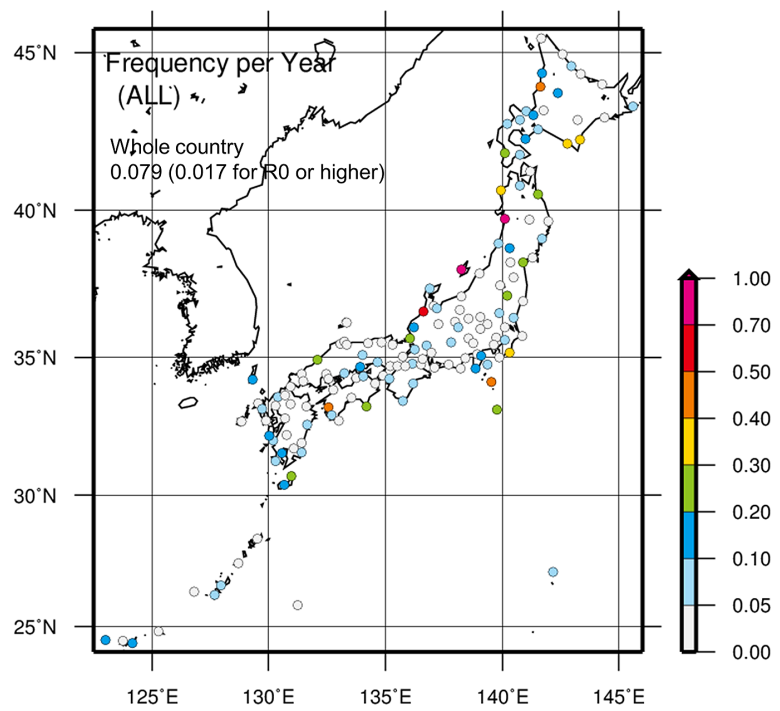

Fig. 16. As in Fig. 7a, but for STPSWs.

conditions, where $z_{a}$ is the anemometer height and $z_{0}$ is the surface roughness. Due to the fact that the definition of wind gust in this study largely depends on the gust factor, as noted in Section 2.2, the relationship between the frequency of wind gusts and the value of $1 / \ln \left(z_{a} / z_{0}\right)$ at weather observatories was investigated. The surface roughness was calculated according to Kondo and Yamazawa (1986) and Kuwagata and Kondo (1990), using national land numerical information with a $100 \mathrm{~m}$ mesh issued by the National Spatial Planning and Regional Policy Bureau in 2014. The land utilization with a $100 \mathrm{~m}$ mesh includes 12 types such as urban and building sites, cropland, and forest. The surface roughness at the observatories was calculated, on average, within a radius of $100 \times z_{a}$ (note

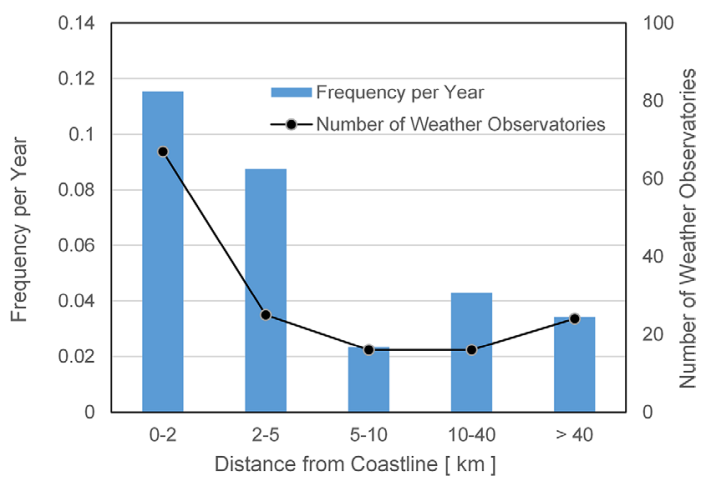

Fig. 17. As in Fig. 8, but for STPSWs.

that the maximum value is $2,500 \mathrm{~m}$ ), considering the effects of these land use types on the surface roughness.

Figure 20 shows the relationship between the frequency of wind gusts and $1 / \ln \left(z_{a} / z_{0}\right)$ at the weather observatories. Although there is a large variation, the value of $1 / \ln \left(z_{a} / z_{0}\right)$ shows no correlation with the frequency of wind gusts. This may be because a large portion of the wind gusts in this study occur under highly unstable atmospheric conditions and are associated with microscale phenomena, in contrast to gusty winds caused by near-surface turbulences in a synoptic-scale disturbance, as reported by Kuwagata (1993). Moreover, the 10-min mean wind speed is likely to weaken at observatories with a large value of $1 / \ln \left(z_{a} / z_{0}\right)\left(z_{a}\right.$ is low and/or $z_{0}$ is high). In such a situation, the threshold of the gust factor for the wind gust itself becomes high, as shown in Fig. 2b. Therefore, the frequency of wind gusts does not necessarily have a positive correlation with the value of $1 / \ln \left(z_{a} / z_{0}\right)$ at the observatories.

Although the environment at the weather observatories apparently has little impact on the frequency of wind gusts, the surrounding environment, such as the influence of topography, might affect the wind gust occurrences (Haginoya et al. 1984). In order to investigate the topographical effect, the prevailing wind direction just after wind gusts at each observatory was analyzed by classifying the wind gusts into two types: wind gusts accompanied by precipitation and wind gusts without precipitation (Fig. 21). The data obtained from the rain detection instruments at the observatories were used to check the presence or absence of precipitation. If rain is detected during the period of $10 \mathrm{~min}$ before and after the wind gust, the wind gust is regarded as being accompanied by precipitation. 

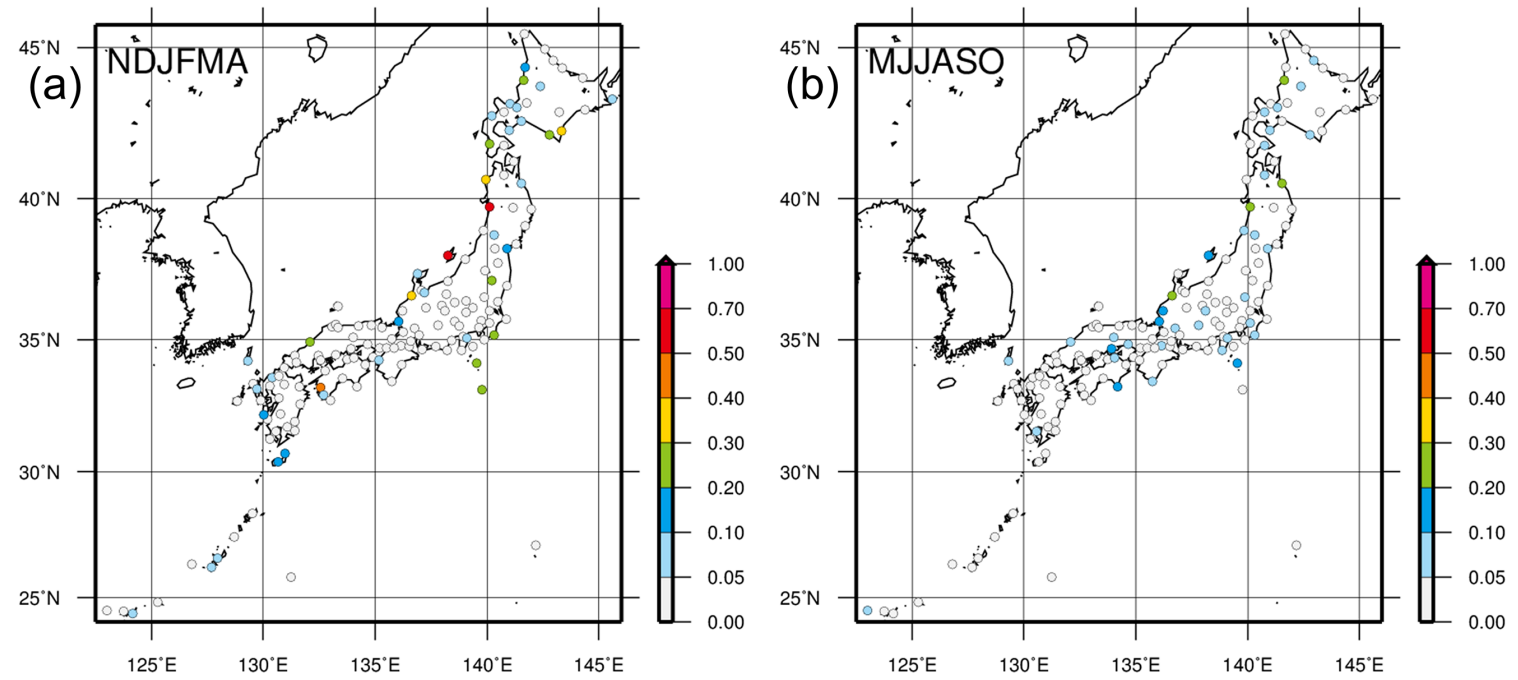

Fig. 18. Annual frequency distribution of STPSWs that are not associated with a typhoon classified into two periods:

(a) November-April and (b) May-October. Note that the unit is frequency per year.
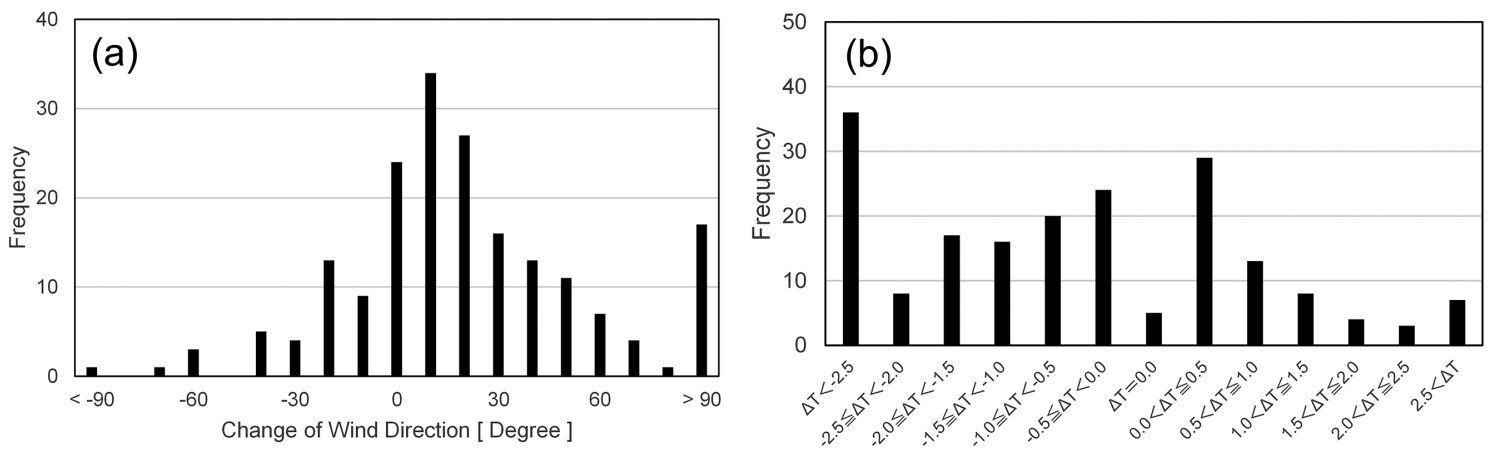

Change of Temperature $\left[{ }^{\circ} \mathrm{C}\right.$ ]

Fig. 19. (a) As in Fig. 13a, but for STPSWs. (b) As in Fig. 14a, but for STPSWs.

It is notable that several observatories on the Pacific side have high-frequency wind gusts, even without precipitation, especially the Ofunato and Hiroo observatories (Fig. 21b). Moreover, the prevailing wind directions at those observatories suggest a land breeze, which indicates that the wind gusts observed at these observatories are largely affected by topography. As noted earlier, around the Ofunato observatory wind gusts were almost never recorded in JMA-DB; however, northwesterly gusty winds without precipitation caused a train derailment near Ofunato observatory on February 1994 (Mitsuta et al. 1995), which gives validity to our results. It is obvious that the prevailing westerly wind at the Hiroo observatory, whether ac- companied by precipitation or not, is influenced by the nearby Hidaka Mountains (see Fig. 1 for the geography around the observatory). The frequency of wind gusts accompanied by precipitation at the Sumoto observatory is high and southerly wind prevails along the Kii Channel; this wind is presumed to be topographically affected. (see Fig. 1 for the geography around the observatory). However, it is estimated that the prevailing westerly wind accompanied by precipitation at the observatories on the Japan Sea side is mainly caused by cold air mass outbreaks from the Eurasian Continent, as indicated in Section 3.1b, rather than the topographical effect. 


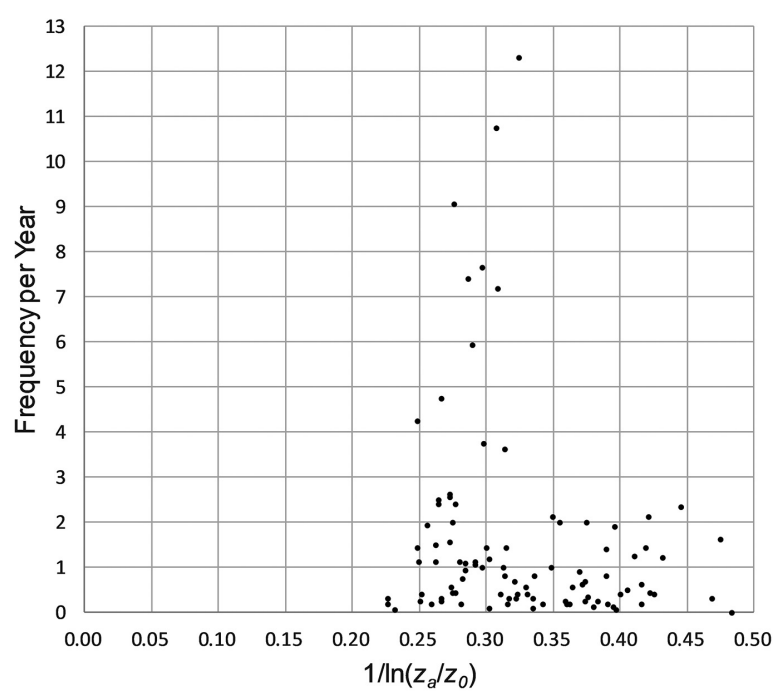

Fig. 20. Relationship between the frequency of wind gusts and $1 / \ln \left(z_{a} / z_{0}\right)$ at the weather observatories, where $z_{a}$ is the anemometer height and $z_{0}$ is the surface roughness. The weather observatories, at which the anemometer was relocated or the anemometer height was changed by more than $1 \mathrm{~m}$ during the analysis period, were omitted in this plot.

\section{Summary}

The statistical characteristics of wind gusts in Japan were investigated using a one-minute interval dataset from 2002 to 2017 recorded at 151 JMA weather observatories. This study is the first to statistically analyze wind gusts using surface meteorological observations throughout Japan. Strict conditions based on the gust factor and amount of increase and decrease in the 3-s mean wind speed from the 10-min mean wind speed are adopted in order to define the wind gust, in contrast to previous studies (Wakimoto 1985; Kobayashi et al. 2008, 2012; Kusunoki et al. 2010; Tomokiyo and Maeda 2016).

As many as 3,531 wind gusts were detected and various statistical characteristics of the wind gusts were investigated. The results are summarized as follows. 1) The frequency of wind gusts averaged over all observatories is 1.47 per year $(0.97$ for R0 strength or higher), which is four or five orders of magnitude higher than the tornado encounter probability in Japan. 2) The coastal regions experience an approximately threefold higher frequency of wind gusts than the inland areas. 3) WGTYs account for approximately half of the wind gusts, and most of the strong wind gusts ranked R1 and R2 are WGTYs. This may suggest that a large portion of typhoon wind damage

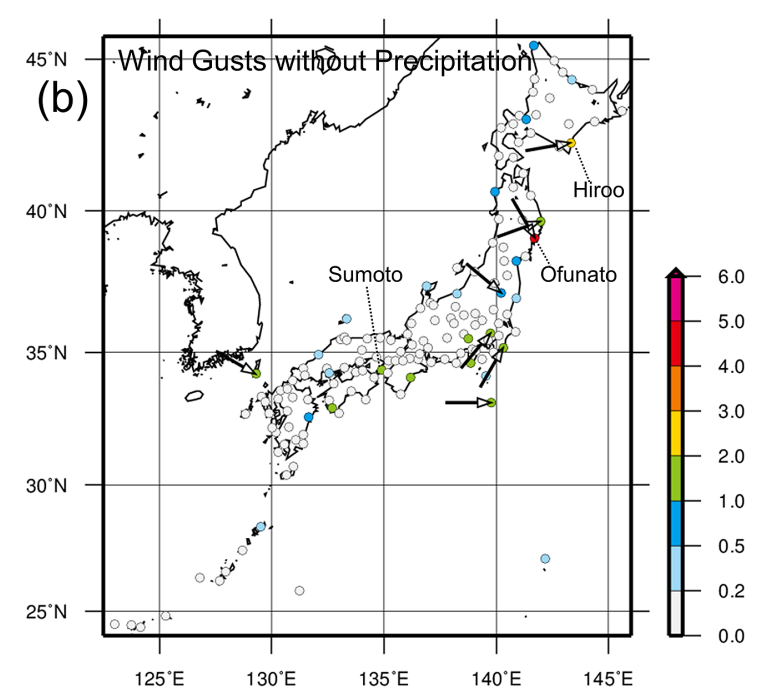

Fig. 21. (a) Prevailing wind direction (arrows; the point of the arrow represents the location of the weather observatory) of Post- $W_{10 \mathrm{~m}}$ of the wind gusts accompanied by precipitation. The prevailing wind direction is plotted when the number of wind gusts is larger than 10 during the analysis period and the most frequent wind direction (36 directions) including plus-minus one direction exceeds $50 \%$ of the total number. The shaded circles indicate the annual frequency of wind gusts accompanied by precipitation at the weather observatories. (b) As in (a), but for the wind gusts without precipitation. 
is caused by these gusty winds. 4) Wind gusts occur most frequently in September and least frequently in June. 5) Approximately $50.8 \%$ of the wind gusts occur between August and October, and most of them are WGTYs. 6) Both WGNoTYs and WGTYs have high activities during daytime, especially between 13:00 and 17:00 JST; however, the diurnal variation is rather small compared with the JMA-DB. 7) Two or more WGTYs often occur on a single day compared with WGNoTYs. 8) The frequency of WGTYs in western Japan is high, whereas the northern and eastern parts of Japan experience a high frequency of WGNoTYs. 9) The Japan Sea coast generally has high-frequency WGNoTYs in winter. 10) Approximately half of the WGTYs occur in the right-front quadrant of a typhoon with respect to the typhoon motion. 11) The WGTYs are likely strong and have a high frequency per unit area within the typhoon core region. 12) Wind gusts generally occur in an environment with small changes in the wind direction and temperature, especially WGTYs. However, wind gusts accompanied by a temperature drop and clockwise shift of the wind direction account for a large portion of all wind gusts.

The statistical characteristics of STPSWs satisfying the same conditions as the wind gusts, but without a rapid decrease in the wind speed, were also examined. The frequency of STPSWs averaged over all observatories is fairly low ( 0.079 per year), and $87.4 \%$ of the STPSWs are not associated with a typhoon. The STPSWs occur most frequently in December, and the frequency in coastal regions of the Japan Sea side is high. The changes in the wind direction and temperature before and after STPSWs are large compared with those of wind gusts, and $40.5 \%$ of STPSWs are associated with a temperature drop of more than $1{ }^{\circ} \mathrm{C}$.

Moreover, the effects of the observational environment on wind gusts were discussed. Although the environment at the weather observatories, such as the anemometer height and surface roughness, has little impact on the frequency of wind gusts, topographic effects likely cause the gusty winds at several observatories.

The wind gusts detected in this study are associated with various phenomena, such as tornadoes, downbursts (e.g., Takemi 2012), gust fronts (or derecho) (e.g., Corfidi et al. 2016), eyewall mesovortices (e.g., Mashiko 2005; Aberson et al. 2006), tornado-scale vortices in the eyewall (Wurman and Kosiba 2018), boundary layer rolls (e.g., Wurman and Winslow 1998), pressure dips (e.g., Fudeyasu et al. 2007), downslope winds (e.g., Saito and Ikawa 1991), and gap winds (e.g., Colle and Mass 2000). There might be an unknown phenomenon causing wind gusts. It remains a challenge for future research to identify which phenomenon causes the wind gusts in Japan.

\section{Acknowledgments}

The author is grateful to Dr. Tetsuya Takemi and two anonymous reviewers for their valuable comments. One-minute interval meteorological data on the weather observatories were provided by the Office of Data and Information Services in JMA. The Global Land Cover Characterization (GLCC) dataset by U.S. Geological Survey was used to specify the coastline of Japanese archipelagos. National land numerical information with $100-\mathrm{m}$ mesh provided by National Spatial Planning and Regional Policy Bureau was used for calculating the surface roughness. This work is partly supported by JSPS KAKENHI Grant Number $15 \mathrm{~K} 05295$.

\section{References}

Aberson, S. D., M. T. Montgomery, M. Bell, and M. Black, 2006: Hurricane Isabel (2003): New insights into the physics of intense storms. Part II: Extreme located wind. Bull. Amer. Meteor. Soc., 87, 1349-1354.

Agee, E., J. Larson, S. Childs, and A. Marmo, 2016: Spatial redistribution of U.S. tornado activity between 1954 and 2013. J. Appl. Meteor. Climatol., 55, 1681-1697.

Antonescu, B., D. M. Schultz, F. Lomas, and T. Kühne, 2016: Tornadoes in Europe: Synthesis of the observational datasets. Mon. Wea. Rev., 144, 2445-2480.

Antonescu, B., D. M. Schultz, A. Holzer, and P. Groenemeijer, 2017: Tornadoes in Europe: An underestimated threat. Bull. Amer. Meteor. Soc., 98, 713-728.

Colle, B. A., and C. F. Mass, 2000: High-resolution observations and numerical simulations of easterly gap flow through the strait of Juan de Fuca on 9-10 December 1995. Mon. Wea. Rev., 128, 2398-2422.

Corfidi, S. F., M. C. Coniglio, A. E. Cohen, and C. M. Mead, 2016: A proposed revision to the definition of "derecho". Bull. Amer. Meteor. Soc., 97, 935-949.

Edwards, R., 2012: Tropical cyclone tornadoes: A review of knowledge in research and prediction. Electron. $J$. Severe Storms Meteor., 7, 1-61.

Fudeyasu, H., S. Iizuka, and T. Hayashi, 2007: Meso- $\beta$-scale pressure dips associated with typhoons. Mon. Wea. Rev., 135, 1225-1250.

Giordano, L. A., and J. M. Fritsch, 1991: Strong tornadoes and flash-flood-producing rainstorms during the warm season in the Mid-Atlantic region. Wea. Forecasting, 6, 437-455.

Glickman, T. S., 2000: Gust. Glossary of Meteorology. 2nd Edition. Amer. Meteor. Soc., 355-356.

Groenemeijer, P., and T. Kühne, 2014: A climatology of tor- 
nadoes in Europe: Results from the European Severe Weather Database. Mon. Wea. Rev., 142, 4775-4790.

Haginoya, N., J. Kondo, and Y. Mori, 1984: Effect of topography on the surface wind speed over the mountainous regions. Tenki, 31, 497-505 (in Japanese).

Japan Meteorological Agency, 2007: Modification in the measuring method of instantaneous wind in Japan Meteorological Agency. Japan Meteorological Agency, 3 pp (in Japanese). [Available at http://www.jma.go.jp/ jma/press/0710/26a/syunkan1026.pdf.]

Kahraman, A., and P. M. Markowski, 2014: Tornado climatology of Turkey. Mon. Wea. Rev., 142, 2345-2352.

Kobayashi, F., K. Shiroiwa, and Y. Ueno, 2008: Statistical characteristics of wind gusts associated with snowband -Observations on the Japan Sea Coast. Tenki, 55, 651-659 (in Japanese).

Kobayashi, F., K. Kawai, T. Hayashi, K. Sasa, and Y. Hono, 2012: Frequency and environmental features of gust in Shonai Plain in winter. J. Wind Eng., 37, 1-10 (in Japanese).

Kondo, J., and H. Yamazawa, 1986: Aerodynamic roughness over an inhomogeneous ground surface. Bound.-Layer Meteor, 35, 331-348.

Krocak, M. J., and H. E. Brooks, 2018: Climatological estimates of hourly tornado probability for the United States. Wea. Forecasting, 33, 59-69.

Kusunoki, K., 2010: A report on 31th conference on mesoscale meteorological phenomena-Wind gusts. Tenki, 57, 171-178 (in Japanese).

Kuwagata, T., 1993: Long term variation of gust factor at the Japanese meteorological station under wind storm condition of strong Typhoon. Tenki, 40, 91-97 (in Japanese).

Kuwagata, T., and J. Kondo, 1990: Estimation of aerodynamic roughness at the regional meteorological stations (AMeDAS) in the central part of Japan. Tenki, 37, 197-201 (in Japanese).

Markowski, P. M., J. M. Straka, and E. N. Rasmussen, 2002: Direct surface thermodynamic observations within the rear-flank downdrafts of nontornadic and tornadic supercells. Mon. Wea. Rev., 130, 1692-1721.

Mashiko, W., 2005: Polygonal eyewall and mesovortices structure in a numerically simulated Typhoon Rusa. SOLA, 1, 29-32.

Mashiko, W., H. Niino, and T. Kato, 2009: Numerical simulation of tornadogenesis in an outer-rainband minisupercell of Typhoon Shanshan on 17 September 2006. Mon. Wea. Rev., 137, 4238-4260.

Mashiko, W., H. Y. Inoue, S. Hayashi, K. Kusunoki, S. Hoshino, K. Arai, K. Shimose, M. Kusume, M. Nishihashi, H. Yamauchi, O. Suzuki, and H. Morishima, 2012: Structure of two adjacent shear lines accompanied by wind gusts in the Japan Sea coastal region during a cold-air outbreak on 12 December 2010.
SOLA, 8, 90-93.

McCaul, E. W., Jr., 1991: Buoyancy and shear characteristics of hurricane-tornado environments. Mon. Wea. Rev., 119, 1954-1978.

Mitsuta, Y., J. Katsura, M. Matsumoto, H. Ishikawa, T. Hayashi, and K. Sugimasa, 1995: On the wind disasters in northern Japan caused by an extratropical cyclone on February, 1994. Ann. Disaster Prev. Res. Inst., Kyoto Univ., 38, 143-161 (in Japanese).

Nagata, M., M. Ikawa, S. Yoshizumi, and T. Yoshida, 1986: On the formation of a convergent cloud band over the Japan Sea in winter: Numerical experiments. $J$. Meteor. Soc. Japan, 64, 841-855.

Nakazato, M., 2016: Overview of the JMA's services related to tornadoes and other hazardous winds. Tenki, 63, 958-961 (in Japanese).

Niino, H., T. Fujitani, and N. Watanabe, 1997: A statistical study of tornadoes and waterspouts in Japan from 1961 to 1993. J. Climate, 10, 1730-1752.

Rauhala, J., H. E. Brooks, and D. M. Schultz, 2012: Tornado climatology of Finland. Mon. Wea. Rev., 140, 1446-1456.

Saito, K., and M. Ikawa, 1991: A numerical study of the local downslope wind "Yamaji-Kaze" in Japan. $J$. Meteor. Soc. Japan, 69, 31-56.

Schultz, L. A., and D. J. Cecil, 2009: Tropical cyclone tornadoes, 1950-2007. Mon. Wea. Rev., 137, 3471-3484.

Takemi, T., 2012: Downburst and gust front: Gusty winds due to cumulonimbus clouds. J. Wind Eng., 37, 172177 (in Japanese).

Tamura, Y., 2016: Establishment of Japanese enhanced Fujita scale (JEF-scale). Tenki, 63, 962-966 (in Japanese).

Tanaka, Y., 2016: Development of Japanese enhanced Fujita scale. Tenki, 63, 833-841 (in Japanese).

Taniwaki, K., K. Sassa, T. Hayashi, Y. Hono, and K. Adachi, 2012: Statistical characteristics of gusty wind conditionally sampled with an array of ultrasonic anemometers. Prog. Turbul. Wind Energy IV, 141, 271-274.

Tomokiyo, E., and J. Maeda, 2016: Selection of short-timerising gust from wind records at AMeDAS and JMA observatory using characteristics of gusts selected from winds from NeWMeK. Proceedings of the 24th National Symposium on Wind Engineering, 24, 1-6 (in Japanese).

Wakimoto, R. M., 1985: Forecast dry microburst activity over the high plains. Mon. Wea. Rev., 113, 1131-1143.

Wurman, J., and J. Winslow, 1998: Intense sub-kilometerscale boundary layer rolls observed in Hurricane Fran. Science, 280, 555-557.

Wurman, J., and K. Kosiba, 2018: The role of small-scale vortices in enhancing surface winds and damage in Hurricane Harvey (2017). Mon. Wea. Rev., 146, 713722 . 